\title{
Introdução ao dossiê Etnologia e Museus: curadorias compartilhadas
}

Laura Pérez Gil

(UFPR)
O presente dossiê é o resultado do I Seminário de Etnologia e Museus organizado pelo Museu de Arqueologia e Etnologia da Universidade Federal do Paraná, que ocorreu em 2015 associado à Semana de Antropologia do Programa de PósGraduação em Antropologia da UFPR. Essa primeira edição do seminário, que terá uma periodicidade anual, foi dedicada a uma reflexão sobre as curadorias compartilhadas. O conceito de curadoria compartilhada, ou colaborativa, é amplo e envolve um conjunto de práticas diversas, que não necessariamente se restringe à montagem de exposições, embora na literatura especializada esse tenha sido 0 foco. $\mathrm{O}$ aspecto central e constitutivo dessas experiências é o envolvimento das comunidades de origem dos objetos que formam os acervos dos museus. Seu surgimento deve ser entendido como um aspecto das mudanças profundas no que se refere à conceitualização e às práticas dos museus que vêm acontecendo nos últimos anos. Trata-se de uma transformação de paradigma que impregna de forma global a orientação e as ações dos museus (Golding 2013; Phillips 2003). Estas mudanças não dizem respeito, exclusivamente, às relações entre museus e comunidades, mas de uma forma mais ampla à relação com o público, à missão dos museus e ao seu comprometimento ético com a sociedade. $\mathrm{O}$ conceito de pós-museu proposto por Hooper-Greenhill condensa alguns dos aspectos que definem esta transformação de paradigma. Ele se baseia em três pontos: uma nova forma de se aproximar do público por meio de uma compreensão mais sofisticada da complexa relação entre cultura, comunicação, aprendizado e identidade; a promoção de uma sociedade mais justa e igualitária como motivação geral; e a consciência de que a cultura representa, reproduz e constitui identidades e que, portanto, os museus devem desenvolver suas ações com responsabilidade ética dado que propõem poderosas narrativas que impactam na formação de imagens sobre o “Nós" e os "Outros" (Hooper-Greenhill 2007). Nessa perspectiva, o pósmuseu passa de ser um espaço de conservação de objetos, repositório de cultura 
material e mecanismo de construção de identidades nacionais, a ser uma tecnologia que incita experiências e que desencadeia processos de conhecimento, de reflexão e de diálogo (Watermeyer 2012; Phillips 2003). Em certo sentido, tudo se passa como se houvesse um deslocamento do eixo em torno do qual os museus se constituem: um movimento que vai dos objetos às pessoas. Os primeiros se tornam um meio, uma ocasião, em vez de ser um fim. No novo paradigma, a produção de diálogos, a negociação de sentidos e a consideração e inclusão de múltiplas perspectivas são uma condição sine qua non não apenas para a produção de conhecimento e a execução de ações, mas também da condição ética e, em última instância, da razão de ser dos museus.

Nesse novo contexto, as comunidades de origem dos acervos desempenham um novo papel, não apenas, me parece, no que se refere às formas de operar dos museus, mas inclusive na constituição da legitimidade dos mesmos. Por meio de experiências de compartilhamento de espaços, ações e decisões, museus e comunidades se entrelaçam em diálogos que se concretizam em exposições, formação de coleções, publicações, etc., e que se caracterizam por colocar em primeiro plano as dimensões éticas que devem orientar, de um lado, essa relação e, de outro, o que essa relação gera. Promover a cidadania, a valorização da diversidade cultural ou a desconstrução de estereótipos negativos são aspectos éticos da missão dos museus destacados por autores que teorizam sobre as curadorias colaborativas (Golding 2013). É interessante notar que, apesar da marca colonial das instituições museais, essa dimensão ética não é, necessariamente, uma novidade na área da etnologia indígena. No contexto brasileiro, por exemplo, um dos princípios que orientou a criação do Museu do Índio, um dos mais representativos do cenário nacional, foi a conceituação humanista de Darcy Ribeiro do museu como instrumento político para a luta dos povos indígenas e como mecanismo para a desconstrução de preconceitos (Abreu 2007). O que o novo paradigma, em desenvolvimento e experimentação, aporta é, de um lado, um descentramento do lócus de emissão das narrativas museográficas e, de outro, a multiplicação de vozes e perspectivas. Uma exposição produzida por meio de uma ação colaborativa não se organiza mais em torno de um discurso unilateral, mas resulta na proposta de uma experiência polifônica, onde perspectivas e formas de conhecimento, nem sempre coerentes entre si, exploram tanto as possibilidades de diálogo como o dissenso (Golding 2013; Herle 2003). Vozes historicamente anuladas, apagadas e reprimidas encontram um espaço de expressão e legitimação, onde podem manifestar sua versão sobre si e sobre o mundo. Do que se trata, afinal de contas, é de avançar na reconstrução conceitual dos museus para que na prática sejam espaços de agenciamento dos coletivos indígenas em vez de instituições que reproduzem a marca colonial. A esse efeito, é necessário que a pluralidade de perspectivas não se esgote na construção da exposição como um processo polifônico no que se refere aos conteúdos, mas que derive também da diversidade dos objetivos e interesses dos envolvidos. Um aspecto ético fundamental, como salienta Phillips (2003), é que cada um dos lados participantes possa definir e obter os benefícios que considere adequados. Colocados esses princípios como orientadores da transfiguração dos museus, seria possível, então, avançar por novos caminhos, como o proposto por Marcos Albuquerque (nesse dossiê): que nos museus se representem experiências coletivas em vez de "culturas" objetificadas. 
Precisamente porque as curadorias compartilhadas implicam a participação de coletivos e sujeitos com saberes-fazeres, interesses, objetivos e histórias diferentes, elas envolvem não apenas transformações éticas, políticas, mas também epistemológicas. Os desafios que se colocam são de ordem prática - a complexidade em termos logísticos, por exemplo -, mas também de ordem conceitual, na medida em que exigem articular conhecimentos que podem ser pensados e sentidos como incompatíveis pelas equipes. Se de um lado são espaços de partilha de conhecimento e de incorporação de novos significados - o contraste entre os critérios de beleza ocidentais e Xikrin evidenciado por Gordon (2011) a partir da visita dos Xikrin à reserva técnica do MAE-USP é um belo exemplo -; de outro, desacordos podem surgir, como a negação por parte dos representantes indígenas a que determinados objetos sejam exibidos ou, inclusive, o questionamento de que façam parte das coleções. Em vários aspectos, uma curadoria compartilhada é um contexto de negociação e, nesse sentido, não há um modelo específico sobre como elas devem acontecer. Constituem espaços e processos de experimentação e adotarão em cada caso feições e soluções particulares.

De forma incipiente, o MAE vem explorando e desenvolvendo nos últimos anos atividades enquadradas na proposta de compartilhar ações e decisões com representantes das populações concernidas com suas coleções. A primeira experiência foi a exposição No ritmo do Fandango, que ocorreu em 2012 no espaço expositivo do MAE em Paranaguá. A exposição envolveu a participação de maestros fandangueiros de Paranaguá tanto na proposta expográfica como nas atividades organizadas em torno da exposição. No que se refere às populações indígenas, em 2013 o MAE convidou um pesquisador indígena kaingang Josué Carvalho para organizar uma coleção de objetos desse grupo para o Museu. O objetivo era, de um lado, dar maior densidade à escassa coleção de objetos kaingang já existente no $\mathrm{MAE}$, e, de outro, agregar perspectivas outras às coleções. A decisão sobre o que iria fazer parte da nova coleção foi definida pela comunidade de origem de Josué Carvalho, como ele mesmo explica no texto que faz parte do presente dossiê. Dentro deste marco, a experiência mais recente foi a exposição Kãchi katukina, que envolveu um amplo conjunto de pessoas: a equipe técnica do MAE (museólogas, administrativos, fotógrafo); a professora do PPGA Edilene Coffaci de Lima; alunos de graduação de diversos cursos (Ciências Sociais, Design, Artes...), alguns deles bolsistas do MAE e outros voluntários; e dois representantes katukina: Nivaldo Mame Rodrigues Katukina e Fábio Wisi Rodrigues Katukina. O longo processo que vai desde a identificação, por parte da etnóloga, do kãchi como uma prática da socialidade katukina até sua constituição como tema de uma exposição e sua inserção como uma nova coleção no acervo do MAE, é analisado no artigo de uma das curadoras, Edilene Coffaci de Lima, à par que um ensaio fotográfico elaborado por Douglas Fróis (técnico do MAE) e vários alunos que na época estavam na graduação e participaram na montagem da exposição e da elaboração de materiais que fizeram parte da mesma, aporta uma reflexão, não mais textual, mas imagética, da mesma.

Nesse marco de exploração de novas formas de ser e fazer dentro de um museu de arqueologia e etnologia, o I Seminário de Etnologia e Museus, um de cujos resultados é o presente dossiê, surge da necessidade de contar com um espaço de reflexão, diálogo, debate e partilha de experiências e propostas de curadorias colaborativas. A mesa redonda contou com a participação de Edilene Coffaci de Lima, Josué Carvalho - a cujas reflexões me 
referi acima - e César Gordon, que contribuiu com uma análise sobre sua participação em uma experiência pioneira no Brasil envolvendo os Xikrin, a coleção de objetos Xikrin elaborada por Lux Vidal, e o MAE-USP (Silva \& Gordon 2011). Não posso deixar de notar, entretanto, que por muito promissores que sejam esses incipientes caminhos, que nos permitem vislumbrar o futuro dos museus etnológicos a partir de princípios éticos, políticos e epistemológicos mais justos e simétricos - num sentido latouriano -, não podemos deixar de ter presente que os museus são, no presente, instituições marcadas pelo passado e por paradoxos ainda operativos. Os artigos de Marcos Albuquerque - a versão escrita da conferência que nos brindou no Seminário -, e os textos de Aline Rabelo e Ryanddre de Souza, que foram apresentados no GT temático sobre antropologia dos objetos, patrimônio e museus -, apontam para a necessidade de mantermos, a todo momento, uma postura crítica e reflexiva. Suas análises sobre os processos através dos quais os acervos e os museus etnográficos foram criados ressaltam o fato de que eles se constituem dentro de contextos e como instrumentos do domínio colonial, e arrastam essa marca ao longo da sua história; ela está inscrita nos acervos, nos procedimentos e nas histórias institucionais. Os desafios que colocam as curadorias colaborativas não se limitam, portanto, à articulação das perspectivas das equipes dos museus com interesses, conhecimentos e formas de fazer diferentes, que procedem de pessoas que até agora foram vistos como "objetos" de conhecimento mais do que como agentes; para além disso, é urgente uma tarefa de desmontagem. Dificilmente práticas verdadeiramente colaborativas são possíveis enquanto elementos como a assinatura colonial ou o dispositivo de autenticidade, analisados por Marcos Albuquerque, não sejam desarticulados.

Laura Pérez Gil é professora adjunta no Departamento de Antropologia da Universidade Federal do Paraná e responsável pela Unidade de Etnologia Indígena do Museu de Arqueologia e Etnologia da mesma universidade. 


\section{REFERÊNCIAS BIBLIOGRÁFICAS}

ABREU, Regina. 2007. "Museus, patrimônios e diferenças culturais". In Regina Abreu, Mário de Souza Chagas e Myrian Sepúlveda dos Santos (eds.). Museus, coleções e patrimônios: narrativas polifônicas. Rio de Janeiro: Garamond, MinC/ IPHAN/DEMU.

GOLDING, Viv. 2013. "Collaborative Museums: Curators, Communities, Collections". In Viv Golding e Wayne Modest (eds.). Museums and Communities Curators, Collections, and Collaboration. London \& New York: Bloomsbury.

GOLDING, Viv \& MODEST, Wayne. 2013. "Introduction". In Viv Golding e Wayne Modest (eds.). Museums and Communities Curators, Collections, and Collaboration. London \& New York: Bloomsbury.

GORDON, César. 2011. "Em nome do belo: o valor das coisas xikrin-mebêngôkre". In César Gordon \& Fabíola A. Silva (orgs.). Xikrin: uma coleção etnográfica. São Paulo: Edusp.

HERLE, Anita. 2003. "Objects, agency and museums: continuing dialogues between the Torres Strait and Cambridge". In Laura Peers \& Alison K. Brown (eds.). Museums and source communities : a Routledge reader. London \& New York: Routledge.

HOOPER-GREENHILL, Eilean. 2007. Museums and Education. Purpose, Pedagogy, Performance. London \& New York: Routledge.

PHILLIPS, Ruth B. 2003. "Introduction: Part III - Community collaboration in exhibitions: toward a dialogic paradigm". In Laura Peers e Alison K. Brown (eds.). Museums and Source Communities. A routledge Reader. London \& New York: Routledge.

SILVA, Fabíola \& GORDON, César (eds.). 2011. Xikrin. Uma coleção etnográfica. São Paulo: Edusp.

WATERMEYER, Richard 2012. "A conceptualisation of the post-museum as pedagogical space". Journal of Science Communication 11(1). 